\title{
Isolated pancreatic metastasis from rectal cancer: a case report and review of literature
}

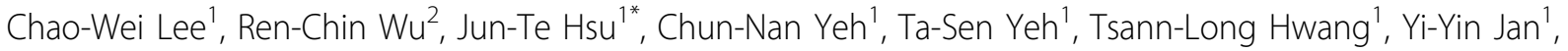 \\ Miin-Fu Chen ${ }^{\prime}$
}

\begin{abstract}
Isolated pancreatic metastases from a non-pancreatic primary malignancy are very rare. Studies have shown that resection of metastases is of proven benefit in some types of tumors. We report a case of 76-year-old Taiwanese woman with rectal adenocarcinoma treated with neoadjuvant chemoradiotherapy and abdominoperineal resection 2 years ago presenting with an asymptomatic mass at the pancreatic tail on a routine follow up abdominal computed tomography scan. The patient underwent distal pancreatectomy and splenectomy under the preoperative impression of a primary pancreatic malignancy. Histological examination of the surgical specimen showed metastatic adenocarcinoma. Immunohistochemical studies confirmed the diagnosis of pancreatic metastasis from rectal adenocarcinoma. Postoperative chemotherapy in the form of oral capecitabine was given. The patient is alive and disease free 12 months after the surgery. In a patient presenting with a pancreatic mass with history of a non-pancreatic malignancy, a differential diagnosis of pancreatic metastasis should be considered. Surgical resection of a solitary pancreatic mass is justified not only to get the definitive diagnosis but also to improve the survival.
\end{abstract}

\section{Background}

The common sites of metastasis from colorectal adenocarcinoma are the liver, lung, and regional lymph nodes [1]. Colorectal adenocarcinoma, however, rarely metastasize to the pancreas. Isolated pancreatic metastases from nonpancreatic primary tumors are very rare, accounting for approximately $2 \%$ of all pancreatic neoplasms [2]. Renal cell carcinoma is the most common primary malignancy to metastasize to the pancreas [3-5]. Studies have shown that surgical resections of hepatic or lung metastases for colorectal malignancy patients provide survival benefit [1]. However, the role of surgery for a solitary pancreatic metastasis from colorectal adenocarcinoma has not yet been defined because of the rarity of the condition. To the best of our knowledge, very few colorectal malignancy cases with pancreatic metastases are reported in the literature [3-7]. Herein, we report a case with primary rectal adenocarcinoma with metachronous pancreatic metastasis undergoing surgical resection and also conduct a substantial review of the literature relevant to pancreatic metastases from colorectal malignancy.

\footnotetext{
* Correspondence: hsujt2813@adm.cgmh.org.tw

'Department of Surgery, Chang Gung Memorial Hospital at Linkou, Chang Gung University College of Medicine, Taoyuan, Taiwan
}

\section{Case Presentation}

A 76-year-old Taiwanese woman had undergone neoadjuvant chemotherapy/radiotherapy and abdominoperineal resection for rectal adenocarcinoma (stage IIIa; pT3N0 M0 according to the 6th edition AJCC; Figure 1) 2 years ago. No post-operative adjuvant chemotherapy or radiotherapy was administered to the patient. She was relatively well postoperatively, without any evidence of disease recurrence or associated symptoms until she was incidentally found to have a mass in the pancreatic tail on a routine follow up abdominal computed tomography scan.

On admission, physical examination, hematogram and biochemistry tests were unremarkable, except for a midline operative scar and an end-colostomy. The carcinoembryonic antigen level $(2.16 \mathrm{ng} / \mathrm{ml})$ was within normal range. Abdominal computed tomography revealed an ill-defined hypodense mass measuring $3.0 \times$ $1.6 \mathrm{~cm}$ in diameter at the pancreatic tail (Figure 2). There was no evidence of local recurrence of rectal cancer, lymphadenopathy or distant metastasis. A primary pancreatic malignancy was suspected, and the patient underwent distal pancreatectomy with splenectomy.

Macroscopically, the cut surface of the pancreatic mass demonstrated a whitish, firm, and infiltrating 


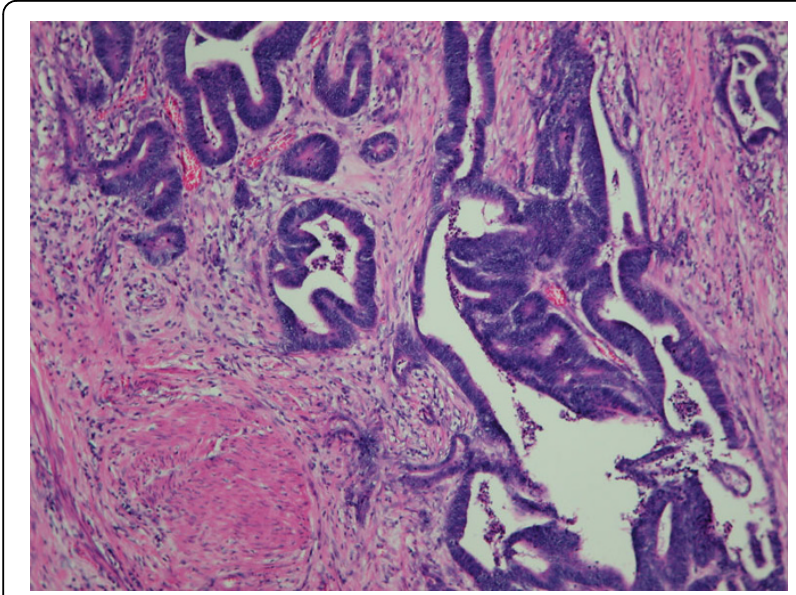

Figure 1 Histological specimen of primary rectal cancer demonstrates a moderately-differentiated adenocarcinoma with invading through the muscularis propria into the subserosa (hematoxylin and eosin staining, 20x).

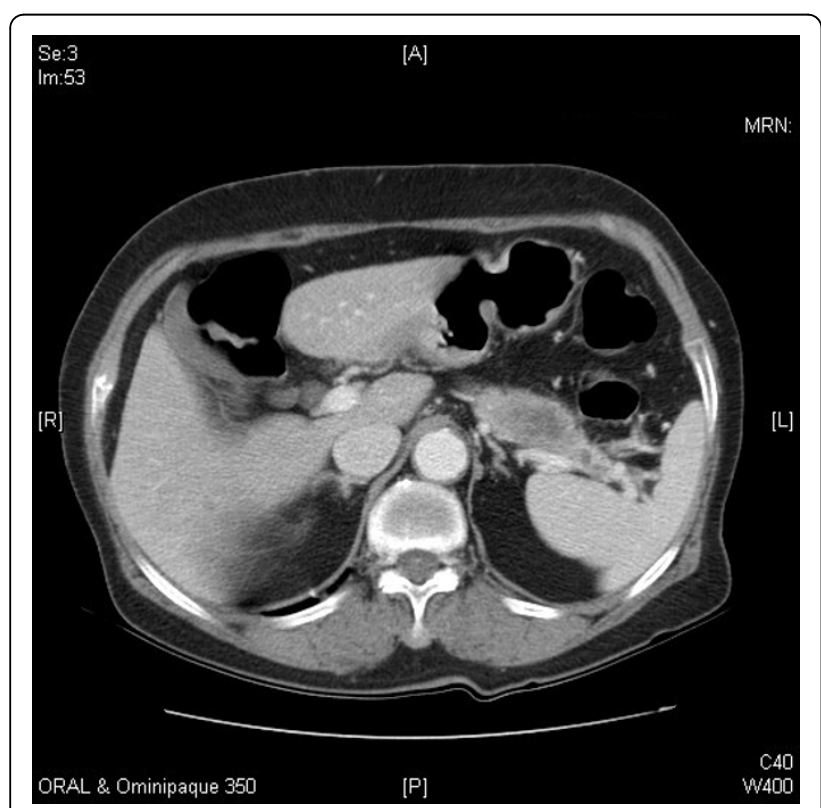

Figure 2 Abdominal computed tomography reveals an illdefined hypodense mass approximately $3.0 \times 1.6 \mathrm{~cm}$ in diameter in the pancreatic tail

tumor with ill-defined margins. Histopathological exam showed a moderately differentiated adenocarcinoma with marked necrosis (Figure 3A) which was morphologically the same as the primary rectal adenocarcinoma. Immunohistochemical studies showed the tumor cells positive for CK-20 (Figure 3B) and CDX-2 (Figure 3C), markers for colorectal adenocarcinoma, confirming the final diagnosis of pancreatic metastasis from rectal adenocarcinoma.

The postoperative course was uneventful except for fever which developed 3 weeks after surgery. Abdominal computed tomography revealed a fluid collection, $3 \mathrm{~cm}$ in size near the pancreatic stump suggestive of intraabdominal abscess and the patient recovered with antibiotic treatment. Post operative chemotherapy in form of oral capecitabine was given and the patient is alive and disease free 12 months after surgery.

\section{Conclusions}

The incidence of pancreatic metastases in autopsy series performed in patients with malignant neoplasms ranged from $1.6-11 \%$ [8]. Renal cell carcinoma is the most common primary tumor, followed by lung cancer (adenocarcinoma and non-small cell lung carcinoma), lobular breast carcinoma, and more rarely, gastric cancer, melanoma, and soft-tissue sarcoma [3,6-11]. Solitary metastases to the pancreas occur even less frequently. Roland et al reported that 27 out of 1,357 (2\%) non-pancreatic tumor patients had solitary pancreatic metastases, and resections were performed in only 4 patients [12]. Nakeeb at al showed that among 363 pancreatoduodenectomies (239 performed for malignant periampullary diseases), metastatic pancreatic tumors were identified in 6 cases (1.65\%) [13]. Faure et al examined 269 pancreatic resections and found solitary pancreatic metastases in 8 cases (2.97\%) [14]. In another study by Sperti et al, isolated pancreatic metastases were noted in 8 of 259 pancreatectomies (3\%) [3]. Colorectal adenocarcinoma, however, was rarely identified to metastasize to the pancreas in those studies. Table 1 summarizes the details of colorectal adenocarcinoma cases with isolated metastasis to the pancreas in the literature and only 8 rectal adenocarcinoma cases including our patient were identified.

Clinical presentations of colorectal tumor patients with isolated pancreatic metastases are quite different from that of primary pancreatic malignancy patients who frequently have abdominal pain, body weight loss, and jaundice $[7,12]$. As shown in table 1 , only 4 patients $(4 / 20,20 \%)$ with pancreatic metastases presented abdominal pain and 1 had body weight loss $(1 / 20,5 \%)$. Six of 20 patients (30\%) manifested jaundice which might be related to tumor location at the pancreatic head with mass effects $[4,5,7,10,12,13,15-22]$. Interestingly, 6 of 11 patients $(54.5 \%)$ with tumor location at the pancreatic head did not present jaundice. However, it was remarkable that up to $45 \%$ of patients $(9 / 20)$ were asymptomatic upon presentation. It was also reported that imaging studies are unable to differentiate primary pancreatic lesions from metastases by any specific manners $[23,24]$. These observations and findings suggested that if one had history of a non-pancreatic primary malignancy presenting a pancreatic mass with unusual manifestations during follow-up, solitary pancreatic metastasis, in addition to primary pancreatic malignancy, should be considered. 


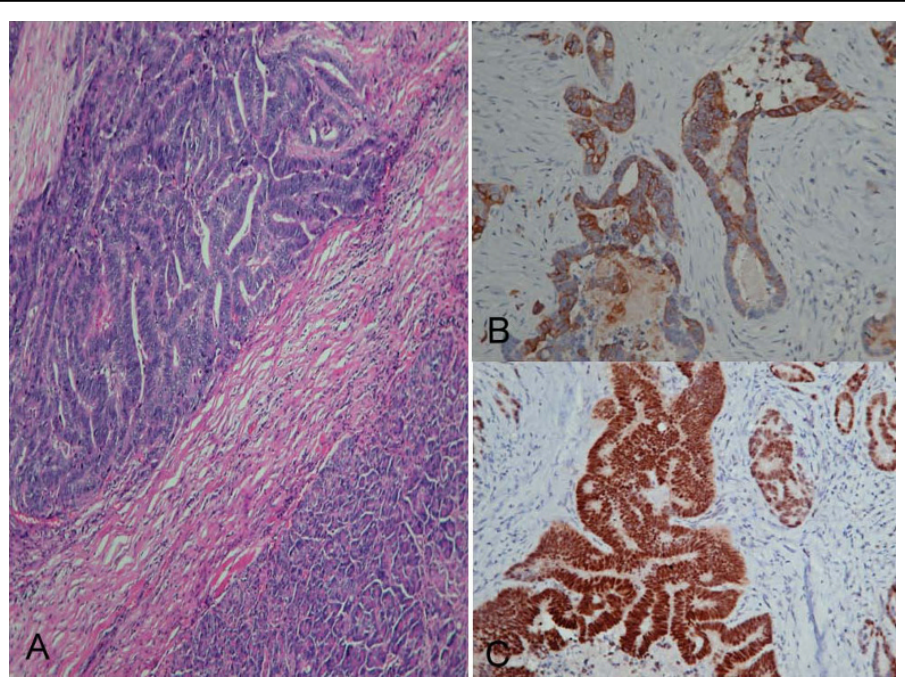

Figure 3 Photomicrography of the pancreatic mass depicts a moderately differentiated adenocarcinoma with marked necrosis (hematoxylin and eosin staining, 20x; A). Immunohistochemial stain studies of the pancreatic tumor shows positive for CK-20 (B) and CDX2 (C), further confirming the diagnosis of metastasis from rectal adenocarninoma.

Table 1 Clinical data of colorectal cancer patients with isolated pancreatic metastases undergoing pancreatic resection in the literature

\begin{tabular}{|c|c|c|c|c|c|c|c|c|}
\hline Authors & $\begin{array}{c}\text { Age } \\
\text { (years) }\end{array}$ & Sex & $\begin{array}{l}\text { Site of } \\
\text { primary } \\
\text { tumor }\end{array}$ & $\begin{array}{l}\text { Interval between primary } \\
\text { tumor and metastases } \\
\text { (months) }\end{array}$ & Symptoms & Site & $\begin{array}{c}\text { Pancreatic } \\
\text { surgery }\end{array}$ & $\begin{array}{c}\text { Survival } \\
\text { (months) }\end{array}$ \\
\hline Roland et al. [12] & - & $F$ & Colon & - & - & Tail & $\mathrm{DP}$ & $27+\dagger$ \\
\hline Nakeeb et al. [13] & 39 & $M$ & Colon & 34 & No & Head & Whipple & 43 t† \\
\hline \multirow[t]{2}{*}{ Harrison et al. [15] } & - & - & Colon & 15 & - & Head & Whipple & 41 ††† \\
\hline & - & - & Colon & 15 & - & Head & Whipple & 21 †十† \\
\hline Inagaki et al. [16] & 79 & $M$ & Rectum & 132 & No & Body-tail & DP & $8+$ \\
\hline Le Borgne et al. [10] & 50 & $M$ & Colon & 60 & Jaundice & Head & Whipple & 12 ††† \\
\hline Tutton et al. [17] & 37 & $M$ & Colon & 23 & No & Tail & DP & $12+$ \\
\hline Torres-Villalobos et al. [18] & 86 & $\mathrm{~F}$ & Cecum & 8 & Body weight loss & Body-tail- & DP & $6+$ \\
\hline Crippa et al. [5] & 50 & $M$ & Colon & 7 & No & Head & PPPD & 13 ††† \\
\hline Matsubara et al. [19] & $50-$ & M & Rectum & 36 & Jaundice & Head & Whipple & 24 ††† \\
\hline Eidt et al. [20] & - & - & Colon & 12 & - & Head & PPPD & 105 †十† \\
\hline Shimada et al. [21] & 54 & M & Rectum & 44 & No & Head & Whipple & 8 †十† \\
\hline \multirow[t]{2}{*}{ Bachmann et al. [22] } & 61 & $\mathrm{~F}$ & Rectum & 24 & Abdominal pain & Tail & $\mathrm{DP}$ & $2+$ \\
\hline & 64 & $F$ & Rectum & 30 & No & Body-tail & DP & $10 \dagger$ \\
\hline Reddy et al.* [4] & - & - & Colon & - & - & - & - & $3.2 \mathrm{yr}^{* *}$ \\
\hline \multirow[t]{9}{*}{ Sperti et al. [7] } & 62 & $M$ & Colon & 48 & Jaundice & Head & Whipple & $31+$ \\
\hline & 71 & $M$ & Colon & 0 (synchronous) & Jaundice & Head & PPPD & $28+$ \\
\hline & 59 & $M$ & Colon & 10 & Jaundice & Head & Whipple & 17 †十† \\
\hline & 62 & $\mathrm{~F}$ & Colon & 36 & Abdominal pain & Tail & DP & $14+$ \\
\hline & 41 & $F$ & Colon & 24 & Abdominal pain & Head & PPPD & 10 ††† \\
\hline & 76 & $F$ & Colon & 0 (synchronous) & Abdominal pain & Head & PPPD & 15 †十† \\
\hline & 77 & $F$ & Colon & 0 (synchronous) & No & Body & $\mathrm{DP}$ & 5 ††† \\
\hline & 48 & $M$ & Rectum & 29 & No & Tail & DP & 30 t† \\
\hline & 57 & $M$ & Rectum & 80 & Jaundice & $\begin{array}{l}\text { Head } \\
\text { Tail }\end{array}$ & $\begin{array}{c}\text { Enucleation } \\
\text { DP }\end{array}$ & 24 ††† \\
\hline Present case & 76 & $F$ & Rectum & 24 & No & Tail & DP & $12+$ \\
\hline
\end{tabular}

-, not available; ${ }^{*}$, two cases with colon cancer; ${ }^{* *}$, median cumulative survival of two cases; $\dagger$, alive; $\dagger+$; alive with disease; †††, dead; DP, distal pancreatectomy; PPPD, pylorus-preserving pancreatoduodenectomy 
In regard of treatment of cancer patients with an isolated distant organ metastasis and the absence of widespread diseases, a number of studies have shown that resection of metastases has been proven beneficial for some types of tumors. For example, metastases to the liver, brain, and lung from tumors such as sarcoma, renal cell carcinoma, colorectal cancer, and gastrointestinal stromal tumors, metastasectomy have been reported to have salutary effects on patient survival [1,25-28]. However the role of surgery for solitary pancreatic metastases from colorectal carcinoma has not yet been well-defined. Given the fact that metastasectomies for colorectal cancer patients with hepatic and pulmonary metastases are beneficial $[1,25]$, it seems to be reasonable to perform pancreatic resections for those patients with isolated pancreatic metastases. Table 1 demonstrated outcomes of patients after pancreatic resections for metastatic colorectal adenocarcinoma with median survival of 16.5 months. Notably, Reddy et al reported that a cumulative median survival of patients after pancreatic resection was more than 3 years [4]. In the current case, surgical resection is reasonable to treat and get the definite diagnosis as well as to improve patient survival. Our patient is alive with disease free more than 12 months after distal pancreatectomy and splenectomy. From a review of surgical outcomes of previously reported cases including our patient and less than $5 \%$ of surgical mortality rate in pancreatic surgery [29], we suggest that pancreatic resection for a solitary pancreatic metastasis from colorectal carcinoma is safe and feasible in a center with high volume of pancreatic surgery. The role of postoperative adjuvant therapy still remains controversial, and further studies are needed to clarify this issue.

Pancreatic metastases should be kept in mind when a patient with history of a non-pancreatic malignancy, such as colorectal adenocarcinoma presenting a pancreatic mass. Long-term follow-up with appropriate imaging studies is mandatory to detect the distant metastasis including the pancreas. Pancreatic resection for an isolated pancreatic metastasis from colorectal adenocarcinoma is feasible in selected cases. Surgical resection of a solitary pancreatic mass is justified not only to get the definitive diagnosis but also to improve the survival.

\section{Consent}

Written informed consent was obtained from the patient for publication of this case report and any accompanying images. IRB approval was also obtained for collecting the data.

\section{Author details}

'Department of Surgery, Chang Gung Memorial Hospital at Linkou, Chang Gung University College of Medicine, Taoyuan, Taiwan. ${ }^{2}$ Department of Pathology, Chang Gung Memorial Hospital at Linkou, Chang Gung University College of Medicine, Taoyuan, Taiwan.

\section{Authors' contributions}

LCW: data collection and analysis, drafting the manuscript. WRC: pathological review of surgical specimens, preparing histopathological figures. HJT: drafting and revising the manuscript, surgical management of the patient. YCN: revising the manuscript. YTS: revising the manuscript. HTL: revising the manuscript. JYY: revising the manuscript. All authors read and approved final manuscript.

\section{Competing interests}

The authors declare that they have no competing interests.

Received: 27 November 2009 Accepted: 7 April 2010

Published: 7 April 2010

\section{References}

1. Turk PS, Wanebo H: Results of surgical treatment of nonhepatic recurrence of colorectal carcinoma. Cancer 1993, 71:4267-4277.

2. Z'graggen K, Fernandez-del Castillo C, Rattner DW, Sigala H, Warshaw AL: Metastases to the pancreas and their surgical extirpation. Arch Surg 1998, 133:413-417.

3. Sperti C, Pasquali C, Liessi G, Pinciroli L, Decet G, Pedrazzoli S: Pancreatic resection for metastatic tumors to the pancreas. J Surg Oncol 2003, 83:161-166.

4. Reddy S, Edil BH, Cameron JL, Pawlik TM, Herman JM, Gilson MM, Campbell KA, Schulick RD, Ahuja N, Wolfgang CL: Pancreatic resection of isolated metastases from nonpancreatic primary cancers. Ann Surg Oncol 2008, 15:3199-3206.

5. Crippa S, Angelini C, Mussi C, Bonardi C, Romano F, Sartori P, Uggeri F, Bovo G: Surgical treatment of metastatic tumors to the pancreas: a single center experience and review of the literature. World J Surg 2006, 30:1536-1542.

6. Hiotis S, Klimstra DS, Conlon KC, Brennan MF: Results after pancreatic resection for metastatic lesions. Ann Surg Oncol 2002, 9:675-679.

7. Sperti C, Pasquali C, Berselli M, Frison L, Vicario G, Pedrazzoli S: Metastasis to the pancreas from colorectal cancer: is there a place for pancreatic resection? Dis Colon Rectum 2009, 52:1154-1159.

8. Adsay NV, Andea A, Basturk O, Kilinc N, Nassar H, Cheng JD: Secondary tumors of the pancreas: an analysis of a surgical and autopsy database and review of the literature. Virchows Arch 2004, 444:527-535.

9. Medina-Franco H, Halpern NB, Aldrete JS: Pancreaticoduodenectomy for metastatic tumors to the periampullary region. J Gastrointest Surg 1999, 3:119-122.

10. Le Borgne J, Partensky C, Glemain P, Dupas B, de Kerviller B: Pancreaticoduodenectomy for metastatic ampullary and pancreatic tumors. Hepatogastroenterology 2000, 47:540-544.

11. Nakamura E, Shimitzu M, Itoh T: Secondary tumors of the pancreas: clinicopathological study of 103 autopsy cases of Japanese patients. Pathol Int 2001, 51:686-690

12. Roland CJ, van Heerden JA: Nonpancreatic primary tumors with metastasis to the pancreas. Surg Gynecol Obstet 1989, 168:345-347.

13. Nakeeb A, Lillemoe KD, Cameron JL: The role of pancreaticoduodenectomy for locally recurrent or metastatic carcinoma to the periampullary region. J Am Coll Surg 1995, 180:180-182.

14. Faure JP, Tuech JJ, Richer JP, Pessaux P, Arnaud JP, Carretier M: Pancreatic metastasis of renal cell carcinoma: presentation, treatment and survival. J Urol 2001, 165:20-22.

15. Harrison LE, Merchant N, Cohen AM, Brennan MF: Pancreaticoduodenectomy for nonperiampullary primary tumors. Am J Surg 1997, 174:393-395.

16. Inagaki H, Nakao A, Ando N, Kotake K, Imaizumi T, Okuda N, Kaneko T, Kurokawa T, Nonami T, Takagi H: A case of solitary metastatic pancreatic cancer from rectal carcinoma: a case report. Hepatogastroenterology 1998, 45:2413-2417.

17. Tutton MG, George M, Hill ME, Abulafi AM: Solitary pancreatic metastasis from a primary colonic tumor detected by PET scan: report of a case. Dis Colon Rectum 2001, 44:288-290.

18. Torres-Villalobos G, Podgaetz E, Anthon FJ, Remes-Trocheb JM, RoblesDiaz G, NuDez CC: Single pancreatic metastasis from a previously resected carcinoma of the cecum: a case report. Curr Surg 2004, 61:328-330. 
19. Matsubara N, Baba H, Okamoto A, Kurata M, Tsuruta K, Funata N, Ashizawa K: Rectal cancer metastasis to the head of the pancreas treated with pancreaticoduodenectomy. I Hepatobiliary Pancreat Surg 2007, 14:590-594.

20. Eidt S, Jergas M, Schmidt R, Siedek M: Metastasis to the pancreas-an indication for pancreatic resection? Langenbecks Arch Surg 2007, 392:539-542.

21. Shimoda M, Kubota K, Kita J, Katoh M, Iwasaki Y: Is a patient with metastatic pancreatic tumor from rectal cancer a candidate for resection? Hepatogastroenterology 2007, 54:1262-1265.

22. Bachmann J, Michalski CW, Bergmann F, Buchler MW, Kleef J, Friess H: Metastasis of rectal adenocarcinoma to the pancreas: two case reports and a review of the literature. JOP 2007, 8:214-222.

23. Boudghene FP, Deslandes PM, Leblanche AF: US and CT imaging features of intrapancreatic metastasis. J Comp Assist Tomogr 1994, 18:905-910.

24. Charnsangavej C, Whitley NO: Metastasis to the pancreas and peripancreatic lymph nodes from carcinoma of the right side of the colon: CT findings in 12 patients. Am J Roentgenol 1993, 160:49-52.

25. Abdel-Misih SR, Schmidt CR, Bloomston PM: Update and review of the multidisciplinary management of stage IV colorectal cancer with liver metastases. World J Surg Oncol 2009, 7:72.

26. Poston GJ: Surgical strategies for colorectal liver metastases. Surg Oncol 2004, 13:125-136.

27. Weitz J, Blumgart $L H$, Fong $Y$, Jarnagin WR, D'Angelica $M$, Harrison $L E$, DeMatteo RP: Partial hepatectomy for metastases from noncolorectal, nonneuroendocrine carcinoma. Ann Surg 2005, 241:269-276.

28. Hart M, Grant R, Walker M, Dickinson H: Surgical resection and whole brain radiation therapy versus whole brain radiation therapy alone for single brain metastases. Cochrance Database Syst Rev 2005, 1:CD003292.

29. Varker KA, Muscarella P, Wall K, Ellison C, Bloomstone M: Pancreatectomy for non-pancreatic malignancies results in improved survival after RO resection. World J Surg Oncol 2007, 5:145.

\section{doi:10.1186/1477-7819-8-26}

Cite this article as: Lee et al:: Isolated pancreatic metastasis from rectal cancer: a case report and review of literature. World Journal of Surgical Oncology 2010 8:26.

\section{Submit your next manuscript to BioMed Central and take full advantage of:}

- Convenient online submission

- Thorough peer review

- No space constraints or color figure charges

- Immediate publication on acceptance

- Inclusion in PubMed, CAS, Scopus and Google Scholar

- Research which is freely available for redistribution 